\title{
Bermuda Grass Pollen IgG Measurement
}

National Cancer Institute

\section{Source}

National Cancer Institute. Bermuda Grass Pollen Ig G Measurement. NCI Thesaurus. Code C130070.

A measurement of the Bermuda grass (Cynodon dactylon) pollen Ig $G$ in a biological specimen. 